\title{
40-Cycle RT-PCR Test for Covid 19: A Weapon of Mass Destruction?
}

\author{
Alejandro Sousa* \\ University of Santiago de Compostela, Comarcal Hospital of Monforte (Monforte-Lugo), Spain \\ *Corresponding author: Alejandro Sousa, University of Santiago de Compostela, Comarcal Hospital of Monforte \\ (Monforte-Lugo), Spain
}

\begin{tabular}{|c|c|}
\hline ARTICLE INFO & ABSTRACT \\
\hline Received: 慧 January 18, 2021 & $\begin{array}{l}\text { Citation: Alejandro Sousa. 40-Cycle RT-PCR Test for Covid 19: A Weapon of Mass } \\
\text { Destruction?. Biomed J Sci \& Tech Res 33(4)-2021. BJSTR. MS.ID.005420. }\end{array}$ \\
\hline
\end{tabular}

\section{Mini Review}

On December 31, 2019, the Chinese health authorities notified the World Health Organization (WHO) of the appearance of cases of pneumonia of unknown etiology in the city of Wuhan, HubeiChina. On January 7, 2020, they officially announced that the causative agent was a new coronavirus, whose genomic sequence was published on January 10, 2020 (www.virological.org) [1]. The new coronavirus has been named SARS-CoV-2 by the Committee on Taxonomy of Viruses and it has been stated that it is the cause of "Covid-19" [2,3]. On January 23, 2020 Corman, et al. [4] published online "Detection of 2019 novel coronavirus (2019-nCoV) by realtime RT-PCR" in the magazine Eurosurveillance. From that moment on, all international organizations including the WHO, the CDC, scientists from various universities, pharmaceutical companies and the ministries of health of almost all world governments accepted that article as the standard diagnostic protocol for SARS-nCoV2.

Interestingly, the article was sent to the magazine on January 21,2020 and accepted for publication the next day. So, it is virtually impossible for this article to have been peer-reviewed in such a way that it was not evaluated by independent scientists who determined whether the information, the methods used, and the conclusions obtained were correct. Prof. Drosten and Dr. Reusken belong to the editorial board of Eurosurveillance (https://www. eurosurveillance.org/board) and they bypassed all the usual controls for this type of publication. In addition, several of the authors who signed the article have serious conflicts of interest. Olfert Landt and Marco Kaiser are respectively Managing Director and Scientific Advisor of TIB Molbiol, which was the first company to manufacture the accepted PCR kits for Covid-19 (Light Mix). Similarly, Victor Corman and prof. Drosten hid their work at Labor
Berlin Charité Vivantes GmbH, charged with conducting PCR tests for Covid-19 in Germany.

Finally, this protocol was sent to WHO (Geneva) on January 17,2020 , where it was immediately approved, and where its use worldwide as a diagnostic standard was immediately recommended, almost a week before its publication. At that time, there was no health crisis since no case was known outside of China, so its urgent approval was unjustified and irresponsible. Shortly after, Tedros Adhanom himself, WHO director general, declared on March 16, 2020 that he had "a simple message for all countries: Test, Test, Test" [5] and almost all countries began a massive evaluation of the asymptomatic population with null epidemiological bases for its realization. In November 2020, 22 internationally renowned scientists conducted an external peer review of Corman's paper to independently assess its quality and accuracy. In this publication, Borger, et al. [6] concluded that the article published without guarantees in Eurosurveillance contains nine serious scientific errors and three minor inaccuracies.

The detailed explanation of these scientific errors exceeds the remit of this editorial, which is why they are only listed below.

1) Extremely high concentrations of primers, DNA polymerase and magnesium sulfate. This leads to an increase in nonspecific binding, amplification, and lack of specificity to identify the SARS-CoV-2 virus.

2) Non-specific primers (oscillating letters) that could give rise to various sequences of forward primers and as many inverse ones that are not related at all to SARS-CoV-2, so the test is not a specific tool for its diagnosis. 
3) The test cannot discriminate between the complete virus (infectious) and the viral fragments.

4) A difference of $10{ }^{\circ} \mathrm{C}$ with respect to the annealing temperature of the first pair of RdRp primers (direct and reverse) when it should be $2^{\circ} \mathrm{C}$.

5) The genes chosen were wrong because:

a) They did not represent the entire length of the virus.

b) The E gene is nonspecific and is present in all coronaviruses.

c) The $\mathrm{N}$ gene that at least ensured that it was a SARS-1 or SARs-CoV2 was removed by the WHO from the protocol due to lack of sensitivity.

6) The RdPd gene proposed by Corman, et al. [4] contains too many oscillating letters so that 2 forward primers, 4 different reverse primers and 8 different probes could be synthesized, which provides excessive variability from the point of view of commercial tests to ensure its specificity.

7) The PCR products have not been validated at the molecular level.

8) The PCR test does not contain a single positive control to evaluate its specificity for SARS-CoV-2 or a negative control to exclude the presence of other coronaviruses, which makes the test unsuitable as a specific diagnostic tool to identify SARSCoV-2. Virus

9) The number of cycles is not specified for a test to be positive. Later, the WHO recommended between 40 and 45 cycles, which is totally wrong from a scientific point of view.

Recently, Bruno, et al. [7]. conducted another critical review of the article by Corman, et al. [4] focused on the "Non-specificity of the Real Time RT-PCR test to detect COVID-19" in which to show the inability of the RT-PCR test to discriminate between different coronavirus strains and to confirm the molecular diagnosis of infection with the novel SARS-CoV-2 virus. The Corman, et al. [4] protocol is based on the detection of 3 viral genes: N, E and RdRp. Theoretically, the first two do not detect common human coronaviruses, but betacoronoaviruses associated with bats; however, their studies demonstrated their inability to detect them. Alone, the test for the RdRp gene would be specific to detect SARS$\mathrm{CoV}-2$ coronavirus. However, the results showed that the detection of the RdRp gene is not specific for SARS-CoV-2 because it shares homologies with sequences from other human coronaviruses, animals and genomic sequences present on human chromosomes (similarities between $97-100 \%$ ) that can be cross-reactive with other viruses and genomic sequences present in human chromosomes. Therefore, this test has a high risk of non-specificity associated with false positive results.
In fact, some of the PCR tests for Covid-19 openly recognize the possible interference by Influenza A (H1N1) virus, Influenza $B$ virus (Yamagata), type B respiratory syncytial virus, respiratory adenovirus (types 3 and 7), parainfluenza virus (type B), mycoplasma pneumoniae and chlamydia pneumoniae. But if there is one unanimous criticism worldwide, it is the total incorrectness in the number of cycles used worldwide to diagnose Covid-19. As early as February 2020, Wang Chen, president of the Chinese Academy of Medical Sciences, admitted that "PCR tests are only 30 to $50 \%$ accurate" [8]. However, inexplicably, the PCR test has continued to be performed worldwide with 40 , or even 45 amplification cycles. In April 2020, La Scola, et al. [9] verified that the percentage of positive viral cultures obtained from nasopharyngeal samples (theoretically SARS-CoV2) and the number of cycles at which the infection was detected were inversely correlated. Thus, while with 17 cycles the test was totally accurate, from that number it progressively decreased, reaching an error level of $100 \%$ from cycle 34.

In August 2020, Dr. Anthony Fauci himself, director of the National Institute of Allergy and Infectious Diseases since 1984, publicly admitted to the media that "it was extremely difficult to detect any live virus in a sample (above threshold of 33 cycles)" [10]. However, it took almost a year since the start of this health crisis for the WHO [11] to officially accept that "As the positivity rate for SARS-CoV-2 decreases, the positive predictive value also decreases. This means that the probability that a person who has a positive result (SARS-CoV-2 detected) is truly infected with SARS$\mathrm{CoV}-2$ decreases as the positivity rate decreases, irrespective of the assay specificity. Therefore, healthcare providers are encouraged to take into consideration testing results along with clinical signs and symptoms, confirmed status of any contacts, etc. adding this to that increased number of amplifications "the distinction between background noise and actual presence of the target virus is difficult to ascertain". In fact, there is complete consensus that PCR tests performed with 40 amplification cycles cannot distinguish between "live" viruses and inactive (non-infectious) virus particles and therefore cannot be used as a diagnostic tool.

They also cannot confirm that SARS-CoV2 is the causative agent of clinical symptoms, as the test cannot rule out diseases caused by other microorganisms or even our own genes. Another important aspect for the possible cancellation of this test as a diagnostic method for Covid-19 is the absolute lack of a gold standard with which to compare the test results [12]. In his article Watson states that "only a virus, tested by isolation and purification, can be a solid gold standard, only virus isolation, that is, an unequivocal virus test, can be the gold standard". But such a comparison of the test versus the isolated and purified culture has never been made. In addition, this crop does not seem to exist (or not be available), as has been recognized by the governments of several countries and 
the document of the Center of Disease Control and Prevention. In a document entitled "CDC 2019-Novel Coronavirus (2019-nCoV) Real-Time RT-PCR Diagnostic Panel" [13] and published on July 13, 2020 , it recognizes in the section "Performance characteristics" (page 39) that "Given that currently no quantified virus isolates of 2019-nCoV are available, the assays [diagnostic tests] designed for the detection of 2019-nCoV RNA were tested with characterized strains of full-length RNA transcribed in vitro... ".

Yesterday, January 16, 2021, the very manufacturer of the PCR test promoted by Corman-Drosten [4] (and blessed by WHO) estimates false positive rate at $50 \%$. This literally means that half of the 95 million cases of "infected" and of the 2 million deaths are false and that almost all the decisions made have been totally wrong and counterproductive [14]. Since the beginning of the health crisis, the belief in the validity of these PCR tests has been so strong that it resembles a fanaticism that does not tolerate contradiction on the part of official doctors and scientists when there is already talk of $95 \%$ false positives, especially when it is performed on asymptomatic patients. One of the basic principles of medicine has been to correlate clinical symptoms, physical examination and complementary tests to arrive at any diagnosis of disease. To assume that a totally asymptomatic person is sick with Covid-19 because a PCR test with 40 amplification cycles has been positive is simply a scientific falsehood. If there were few cases, such probably wrong diagnoses would not matter much, but when that error probably involves $2 / 3$ of the almost 95 million people diagnosed with Covid-19 to date, it is an error of monstrous proportions with enormous global social, health and economic repercussions.

Likewise, a significant part of the 2 million deaths from heart attacks, cancer, strokes, trauma and other diseases has been mislabeled as Covid-19 just because of testing positive on a 40-cycle amplified PCR test. Only 6\% of COVID-19 deaths in the United States had COVID-19 as the only cause mentioned, suggesting that 94 percent of patients who died from the coronavirus also had other underlying 2.6 additional conditions per person, according to a new report of the US Centers for Disease Control and Prevention (CDC) [15]. This organism listed severe medical conditions linked to coronavirus deaths, including influenza and pneumonia, respiratory failure, hypertensive disease, diabetes, vascular and unspecified dementia, cardiac arrest, heart failure, renal failure, intentional and unintentional injury. The world economy has presented a serious setback during 2020. GDP declines in the second half of the year have varied between 4 and $22 \%$ with the only, and curious, exception of China whose GDP increased by $4.9 \%$ [16].

The making of political decisions that are clearly inadequate because they are based on mostly erroneous diagnoses, have caused devastating consequences for the country's economy without having produced any health advantage according to studies carried out by various universities in the USA and Europe. These decisions made around the world have pushed 60 million people into "extreme poverty", which is defined as living on less than $\$ 1.90$ per person per day [17]. Said political decisions have been characterized by their notorious arbitrariness, forcing confinements of the population, curfews, perimeter closures, capacity limitations, closure of activities not considered essential and a long list of deleterious decisions for the population that have led to the ruin of millions of families and the closure of numerous small and mediumsized enterprises that are the basis of the productive economy. Most likely, in the not so distant future, the social and economic consequences of these decisions not unsupported by scientific information will be determined in the courts of justice worldwide.

\section{References}

1. Zhang YZ (2020) Novel 2019 coronavirus genome. Virological.

2. WHO (2019) WHO Coronavirus disease (COVID-19) outbreak.

3. Gorbalenya AE, Baker SC, Baric RS, De Groot RJ, Drosten C, et al. (2020) The species Severe acute respiratory syndrome-related coronavirus: classifying 2019-nCoV and naming it SARS-CoV-2. Nat Microbiol 5: 536544 .

4. Corman V, Landt O, Kaiser M, Molenkamp R, Meijer A, et al. (2020) Detection of 2019 novel coronavirus (2019-nCoV) by real-time RT-PCR. Euro Surveill 25(3): pii2000045.

5. WHO (2020) WHO Director-General's opening remarks at the media briefing on COVID-19 - 16 March 2020.

6. Borger P, Malhotra R, Yeadon M, Craig C, Mc Kernan K, et al. (2020) External peer review of the RTPCR test to detect SARS-CoV-2 reveals 10 major scientific flaws at the molecular and methodological level: consequences for false positive results. Zenodo.

7. Bruno R, Schneider E (2020) Inespecificidad del test de RT-PCR en Tiempo Real para detectar COVID-19.

8. Feng C, Hu M (2020) Race to diagnose coronavirus patients constrained by shortage of reliable detection kits. Science \& Research.

9. La Scola B, Le Bideau M, Andreani J, Hoang VT, Grimalder C, et al. (2020) Viral RNA load as determined by cell culture as a management tool for discharge of SARS-CoV-2 patients from infectious disease wards. Eur J Clin Microbiol Infect Dis 39(6): 1059-1061.

10. (2020) Your Coronavirus Test Is Positive. Maybe It Shouldn't Be.

11. WHO (2020) WHO Information Notice for IVD Users 2020/05.

12. Watson J (2020) Interpreting a covid-19 test result. BMJ pp. 369.

13. (2020) CDC 2019-Novel Coronavirus (2019-nCoV) Real-Time RT-PCR Diagnostic Panel.

14. Von Jens Bernert (2021) Der medizinische Scherzartikel.

15. (2020) CDC says 94 percent of COVID-19 deaths in US had underlying conditions.

16. (2020) The virus that shut down the world: Economic meltdown.

17. Dharshini David (2020) Coronavirus 'a devastating blow for world economy'. 
ISSN: 2574-1241

DOI: 10.26717/BJSTR.2021.33.005420

Alejandro Sousa. Biomed J Sci \& Tech Res

(C) This work is licensed under Creative

Submission Link: https://biomedres.us/submit-manuscript.php

$\begin{array}{ll}\text { BIOMEDICAL } & \text { Assets of Publishing with us } \\ \text { RESEARCHES } & \text { - Global archiving of articles } \\ \text { - Immediate, unrestricted online access }\end{array}$

